Quantitative Asessment of Program Outcomes Using Longitudinal Data from the FE Exam

Dr. Joe C. Guarino, Boise State University

Professor of Mechanical and Biomedical Engineering

Prof. James R Ferguson P.E., Boise State University

Associate Professor

Dr. V Krishna C Pakala, Boise State University 


\section{Quantitative Assessment of Program Outcomes Using Longitudinal Data from the FE Exam}

There have been many studies providing details on using results from the Fundamentals of Engineering (FE) exam as metrics for meeting ABET program outcomes ${ }^{1}$. However, implementing an FE-based set of metrics poses challenges not limited to assessing validity of results. Programs using FE-based metrics must also determine the position of the metrics in the overall assessment process. We present a method for using FE-based metrics as an integral part of the ABET program assessment process. The principle issues we address are: (1) The validity of using FE metrics for a group of graduating students when not all of them take the exam; (2) Establishing and quantifying levels of performance; and (3) Creating a trigger mechanism for taking action based upon longitudinal results.

The Department of Mechanical and Biomedical Engineering at Boise State University created a process which integrates metrics from the FE results with other metrics in our loop for outcomes assessment and continuous improvement. Our process prevents us from taking inappropriate action based upon isolated negative results from the FE exam. We have used our process to make a demonstrable improvement in our curriculum. Two examples of faculty action taken due to unsatisfactory and questionable results from the FE metric before our last ABET visit are presented and discussed.

\section{Introduction}

The Fundamentals of Engineering (FE) exam is a common metric used to assess outcomes of engineering programs. The FE exam is an eight-hour, multiple choice exam administered in the fall and spring. The morning part of the exam contains 120 questions in general engineering and related fields. The afternoon part of the exam contains 60 specialized questions relating to the field chosen by examinee. The FE exam provides a nationally-normed metric of student performance in subject areas which can be related to ABET program outcomes. The format of the FE exam has been constant for many years, although the content has varied slightly within well-defined parameters. It is worth noting that the FE exam will change from a pencil-andpaper exam given twice a year to a computer-administered exam available throughout much of the year beginning in January, 2014. Moreover, beginning in January 2014, the entire FE exam will be discipline specific, rather than only the afternoon part ${ }^{2}$. We anticipate that these changes will make the FE exam more accessible and provide a better continuum of data. A recent survey returned by 115 institutions showed that some or all of the engineering programs at $93 \%$ of the responding institutions used the FE exam for ABET assessment ${ }^{3}$.

Our department decided to make the FE exam an integral part of our assessment program with the advent of the ABET 2000 accreditation criteria. However, research and introspection elucidated several concerns regarding the FE exam metric:

- The multiple-choice format precludes in-depth, process-oriented answers

- We don't want our curriculum to be driven by the FE exam 
- Not all of our students take the FE exam

Drnevich et al mention these concerns and others in their paper opposing the mandatory use of the FE exam as an assessment tool ${ }^{4}$.

\section{Methods}

Our department implemented the FE exam metric with due regard to the concerns mentioned in the introduction. We addressed our concerns by establishing requirements for the FE exam metric as shown in Table 1:

Table 1: Requirements for use of the FE exam metric

\begin{tabular}{|l|l|}
\hline Holistic & Must be harmonious with other metrics \\
\hline Representative & Must accurately represent all of our graduates, not just the examinees \\
\hline Longitudinal & Must illustrate trends for benchmarking and for decision making \\
\hline Sensitivity & Must clearly indicate areas of concern \\
\hline Stability & Must not promote changes based upon isolated or non-representative results \\
\hline Trigger & Must have a quantifiable mechanism which causes action to be taken \\
\hline $\begin{array}{l}\text { Dependent } \\
\text { Variable }\end{array}$ & Must not be an “independent variable” that drives our curriculum \\
\hline
\end{tabular}

We do not use the FE exam for every ABET outcome. The FE exam is our principal metric for ABET criteria (a), (e), (f), (h), and (k) ${ }^{5}$ :

a. An ability to apply knowledge of mathematics, science, and engineering

e. An ability to identify, formulate, and solve engineering problems

f. An understanding of professional and ethical responsibility

h. The broad education necessary to understand the impact of engineering solutions in a global and societal context

k. An ability to use the techniques, skills, and modern engineering tools necessary for engineering practice

Assessment methods other than the FE exam are more suitable for ABET criteria (b), (c), (d), (g), (i), and (j). Table 2 shows how our FE metric is embedded with other metrics in our assessment program. The letters "P" and " $\mathrm{S}$ " designate primary and secondary metrics, respectively. Secondary metrics are recorded and archived; however, they are not used for reporting purposes unless the primary metric is incomplete or equivocal. Our metrics are:

SES: $\quad$ Senior Exit Survey

FE: $\quad$ Fundamentals of Engineering (FE) Exam

CDSA: Capstone Design Sponsor Assessment

CRSW: Comprehensive Review of Student Work 
Table 2: ABET Outcomes and Assessment Methods

\begin{tabular}{|c|c|c|c|c|}
\hline ABET Outcome & SES & $\mathrm{FE}$ & CDSA & CRSW \\
\hline $\begin{array}{l}\text { (a) (apply math, science and } \\
\text { engineering) }\end{array}$ & & $\mathbf{P}$ & & $S$ \\
\hline $\begin{array}{l}\text { (b) (conduct and design } \\
\text { experiments) }\end{array}$ & $S$ & & & $\mathbf{P}$ \\
\hline $\begin{array}{l}\text { (c) (design a system, component } \\
\text { or process) }\end{array}$ & $\mathbf{S}$ & & $\mathbf{P}$ & $\mathbf{P}$ \\
\hline (d) (multidisciplinary teamwork) & $\mathbf{S}$ & & $\mathbf{S}$ & $\mathbf{P}$ \\
\hline $\begin{array}{l}\text { (e) (identify and solve eng. } \\
\text { Problems) }\end{array}$ & $S$ & $\mathbf{P}$ & $\mathbf{S}$ & $\mathbf{S}$ \\
\hline $\begin{array}{l}\text { (f) (understand professional } \\
\text { and ethical responsibilities.) }\end{array}$ & & $\mathbf{P}$ & $S$ & $S$ \\
\hline (g) (communicate effectively) & $S$ & & $\mathbf{S}$ & $\mathbf{P}$ \\
\hline $\begin{array}{l}\text { (h) (impact in global and societal } \\
\text { contexts) }\end{array}$ & $S$ & $\mathbf{P}$ & $S$ & $\mathbf{P}$ \\
\hline (i) (life long learning) & $S$ & & & $\mathbf{P}$ \\
\hline $\begin{array}{l}\text { (j) (knowledge of contemporary } \\
\text { issues) }\end{array}$ & & & & $\mathbf{P}$ \\
\hline (k) (modern engineering tools) & & $p$ & $S$ & $\mathbf{P}$ \\
\hline
\end{tabular}

The FE exam provides useful data for ABET outcomes (h) and (k); however, the comprehensive review of student work (CRSW) metric provides detailed information that augments the FE results.

Steadman et al describe several methods to represent the data provided by the FE exam ${ }^{3}$. We use the scaled score (SS) approach because it includes allowances for national standard deviation and for small-sample bias.

The scaled score is the difference between the number of correct questions by examinees at a particular school and all examinees, divided by the standard deviation of scores of all examinees. The formula below describes the scaled score mathematically as it relates to our students:

Scaled Score $=\frac{\text { (\# of questions) }}{100} * \frac{(\text { Our Students \% correct }- \text { National Average \% Correct })}{\text { NationalStandard Deviation }}$

A scaled score of zero coincides with the national average score.

The "standard error" provides a measure of uncertainty for the standard scores. The formula used to compute standard error as it relates to our students is:

Standard Error $= \pm(N)^{-0.5}$; where $\mathrm{N}$ is the number of our students who took the FE exam.

We use a weighted average of scaled scores for each academic year to preclude comparison of results from small numbers of examinees in the fall with results from a much larger number of examinees in the spring. 
Our FE metric is used to evaluate the degree that an outcome is being met, and also to trigger action in the event that an outcome is not being met. The FE metric is longitudinal and has a value from 1 to 5 :

[1] Excellent -Two consecutive years with lower limit of error bar above the national norm

[2] Good - Two consecutive years with scaled scores above the national norm, but error bar lower limit below national norm

[3] Satisfactory - One year with scaled score above/below the national norm, followed by a year with scaled score below/above the national norm

[4] Questionable - Two consecutive years with scaled scores below the national norm, but error bar upper limit above national norm

[5] Unsatisfactory - Two consecutive years with upper limit of error bar below national norm

Examples of values for our FE metric are shown in Figures 1a through 1e.

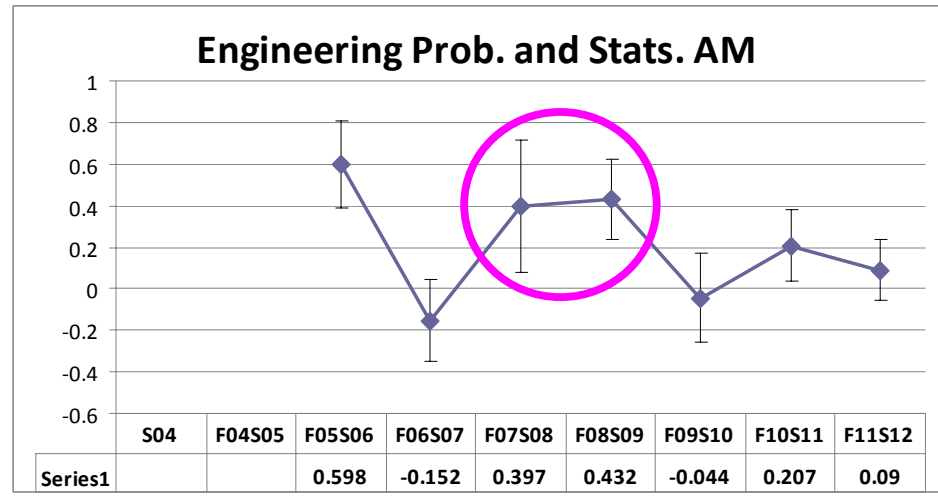

Figure 1a: Excellent [1] FE metric score, academic years 2007 and 2008

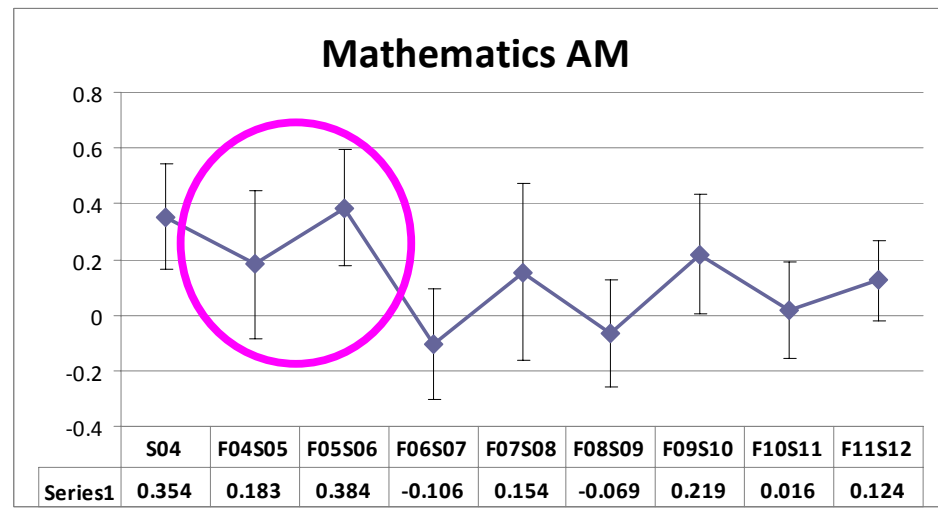

Figure 1b: Good [2] FE metric score, academic years 2004 and 2005 


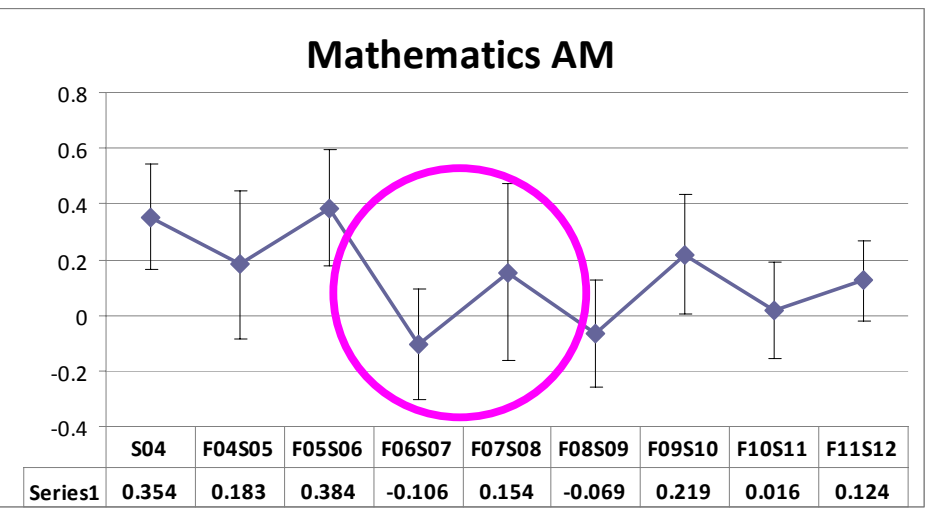

Figure 1c: Satisfactory [3] FE metric score, academic years 2006 and 2007

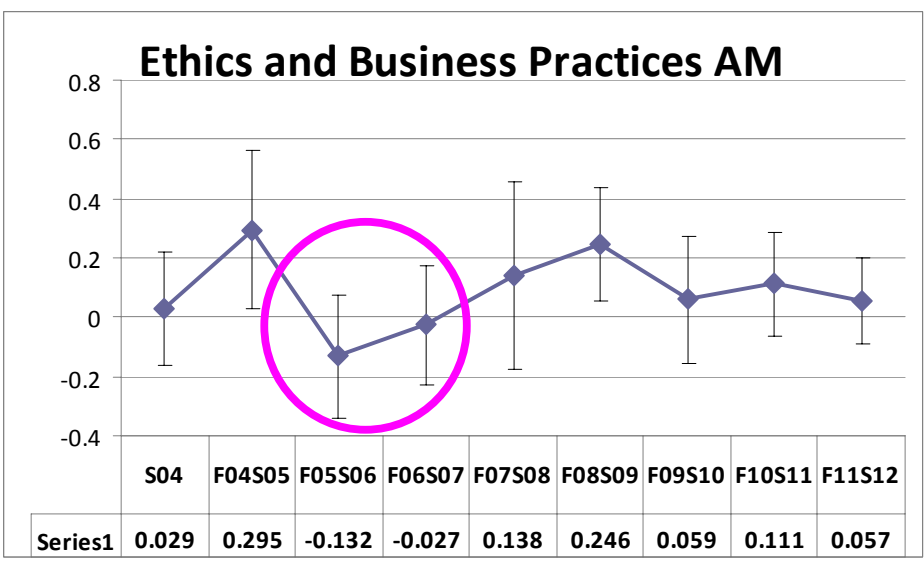

Figure 1d: Questionable [4] FE metric score, academic years 2005 and 2006

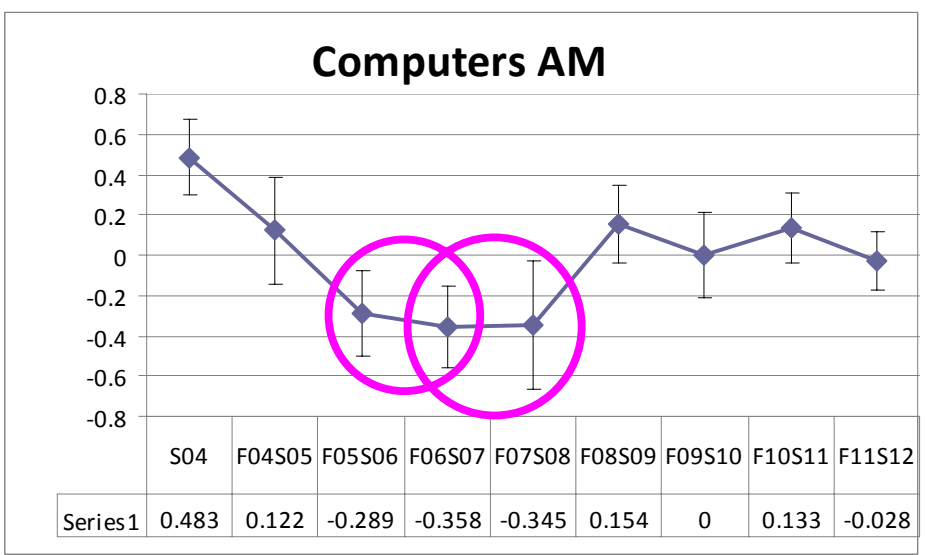

Figure 1e: Unsatisfactory [5] FE metric score, academic years 2005, 2006, and 2006, 2007 
The content of the FE exam, as well as the data provided to us, both change slightly over the years. For example, between spring 2005 and spring 2008, scores for Statics and Dynamics in the morning part of the FE exam were reported to us as one overall value. We preserved continuity by combining scaled scores for Statics and Dynamics prior to Fall 2005. Materials Science/Structure of Matter was removed and Engineering of Materials was added to the general afternoon exam beginning in Fall 2005. We reviewed the subject content of these topics and decided to compare scores directly. Probability and Statistics questions were extracted from the Mathematics section and reported separately in both the morning and general afternoon exams beginning in Fall 2005. Scores in these areas were deemed incomparable; therefore, we now calculate them as separate metrics.

Our department reviews results from the FE metric every year, after the fall and spring FE data are reduced for the previous academic year. We do not take action for FE Exam metrics of [1], [2], and [3]. An FE exam metric of [4] (questionable) causes concern and requires a focused departmental discussion. Other metrics are recalled when necessary to provide perspective. Remedies associated with an FE metric score of [4] may include small changes in the content of one or two courses associated with the subject score. An FE metric score of [5] (Unsatisfactory) indicates to us that the associated outcome is not being met. Remedies associated with an FE metric score of [5] are often systemic, and may involve changes in our curriculum.

We are fortunate that a very large percentage of our students take the FE exam before they graduate. Over our last ABET assessment period (Spring 2004 through Fall 2009), 155 of our 189 students (83\%) took the FE exam before they graduated. However, due to incomplete header information provided by our students on their FE exams, we obtained data from only $72 \%$ of our students (134 out of 186). We wished to verify that the grade-point averages (GPA) of the examinees reflected the overall cohort of graduates; however, the very high percentage of our students taking the FE exam virtually assures a strong correlation using any statistical metric. A more meaningful measure was suggested by Dr. Yonnie Chyung, an Instructional \& Performance Technology professor and expert in assessment techniques ${ }^{6}$. The approach we use to verify that the FE metric accurately measures all of our students is to compare the GPA distribution between all graduates and graduates who took the FE exam while they were students.

\section{Results}

A comparison of GPA distributions between all graduates and those who took the FE exam while they were students over our last accreditation period is provided in Figure 2. 

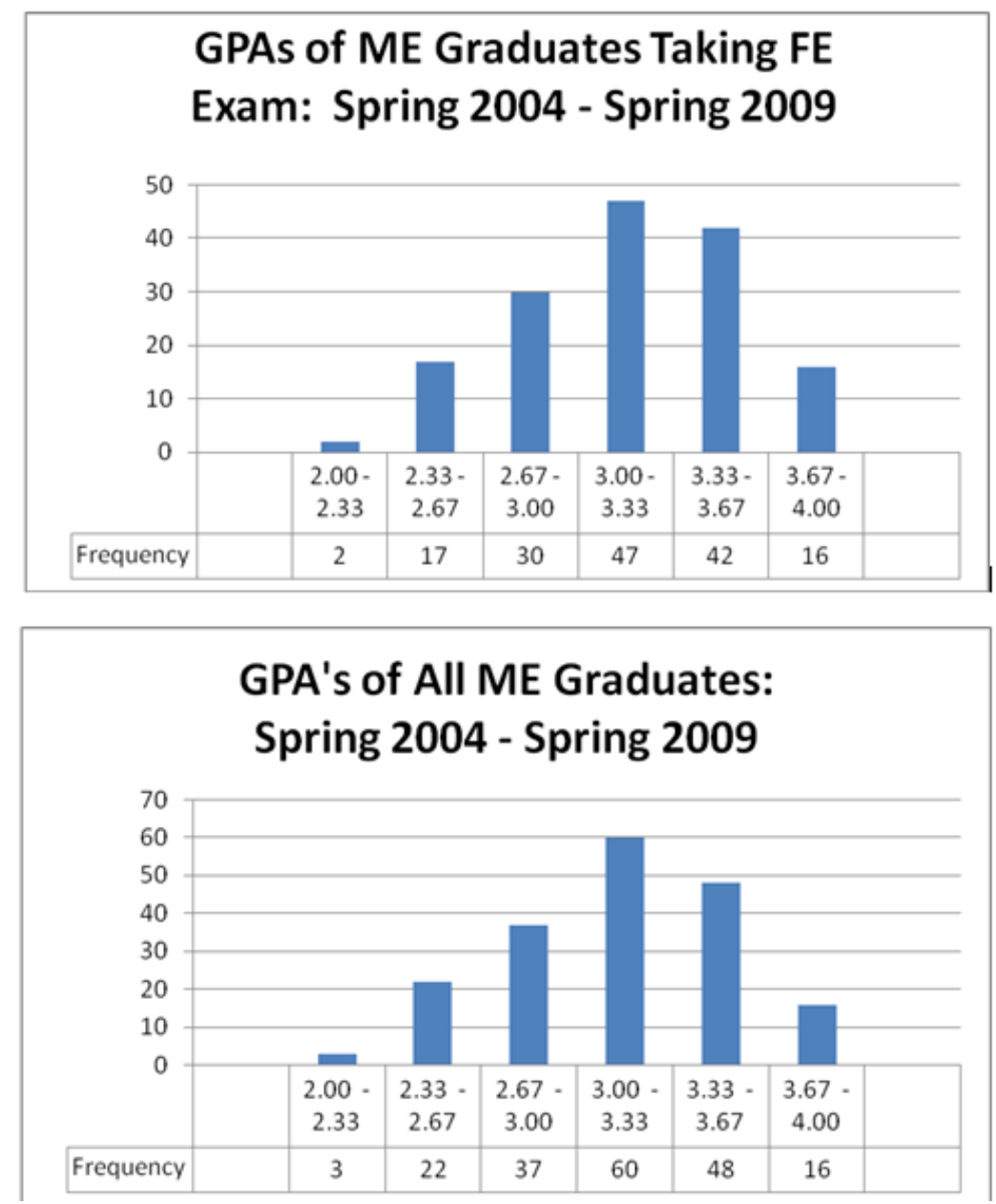

Figure 2: GPA distributions of examinees and all graduates

A qualitative assessment of the GPA distributions led us to conclude that FE results were representative for all of our graduates over the accreditation period.

The FE metric associated with ABET outcome $(\mathrm{k})$ is shown in Figure 3. This metric was unsatisfactory after the 2006 academic year and therefore triggered departmental review and action in the spring semester of 2007. Discussion revealed that students had serious shortcomings in understanding the terminology and functions of basic algorithms (many students did not know about loops, conditional statements, or recursions). However, a faculty review of the CRSW, which is the co-primary metric for ABET outcome $(\mathrm{k})$, demonstrated that students are able to use modern computational resources very well. Faculty generally regarded the FE results as indicative of a narrow (but important) skill set.

We took action by adding a required course in Computer Programming (COMPSCI 117, Introduction to $\mathrm{C}++$ ). COMPSCI 117 was added in Spring 2008; however, faculty agreed to encourage our students to take COMPSCI 117 even if they were graduating under an older catalog. Our FE metric associated with ABET outcome $(\mathrm{k})$ showed a dramatic rise in the 2008 academic year, as shown in Figure 3. 


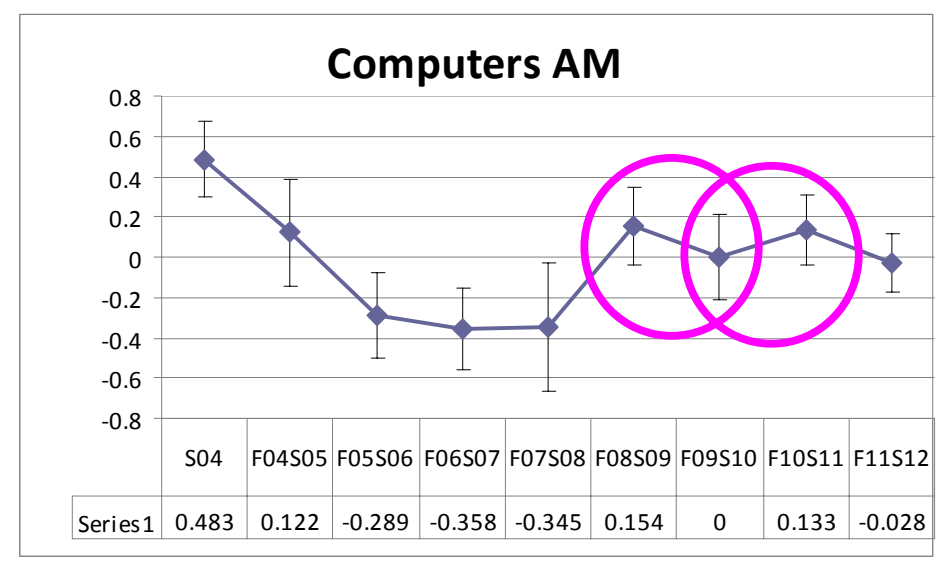

Figure 3: FE metric score improved to Good [2], academic years 2008 and 2009, 2009 and 2010

The FE metric associated with ABET outcome (f) is shown in Figure 4. This metric score was questionable [4] during the academic years 2005 and 2006, with sustained improvement beginning in academic year 2007.

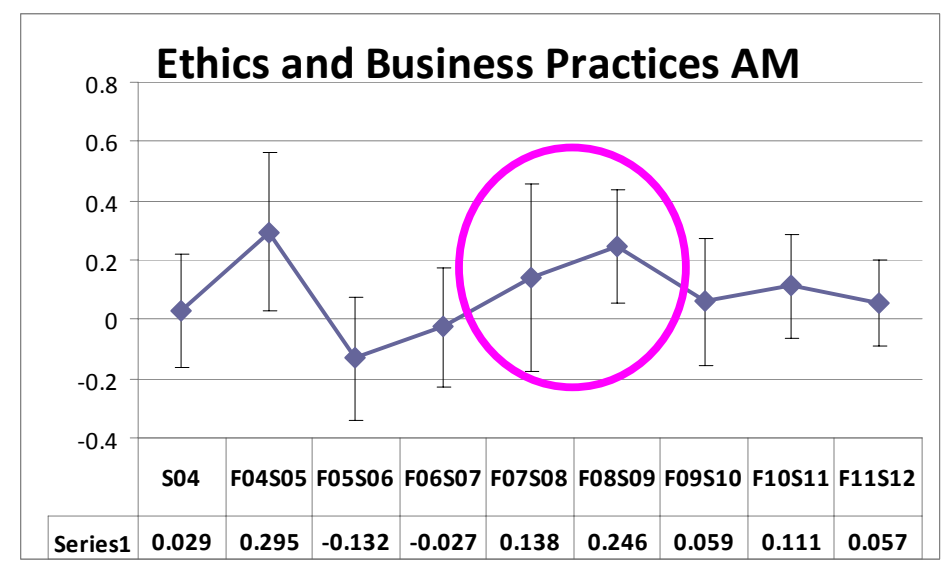

Figure 4: FE metric score improvement to Good[2] beginning academic year 2007 and continuing to present

The FE metric score associated with ABET outcome (f) triggered a faculty discussion in fall 2007. Evidence associated with our secondary metrics for this outcome (Comprehensive Review of Student Work and Capstone Design Sponsor Assessment) was judged by our faculty to be excellent. The upward trend of the FE metric scores from academic year 2005 to academic year 2006, supported by scores associated with our secondary metrics, compelled our decision not to intervene, pending a review of the next set of data from academic year 2007. Coincidentally, a new university core course titled "Ethical Dimensions of Technology" (ENGR 102) was introduced in fall 2007. ENGR 102 immediately became popular with our junior and senior students, who were pleased to use an engineering-related course to help fill their university core requirements. We feel that ENGR 102 had an immediate and sustained positive impact on the FE metric scores associated with ABET outcome (f), starting in academic year 2007. While our department cannot take credit for this improvement, the results help to validate our confidence in the FE metric associated with this ABET outcome. 


\section{Conclusions}

The FE exam is an accepted and vital part of the assessment program in our department. Nationally-normed subject scores provide us with a good indication of our student's performance in engineering and engineering-related areas. We used FE exam results in context with other metrics to improve our curriculum. We envision that the FE metric will be even more relevant when changes beginning in January 2014 provide greater access to the exam.

\section{Bibliography}

1. Barret, S., E. LeFevre, J. Steadman, J. Tietjen, K. White, D. Whitman, "Using the Fundamentals of Engineering (FE) Examination as an Outcomes Assessment Tool,” National Council of Examiners for Engineering and Surveying, June, 2010 .

2. The CBT Experience, http://www.NCEES.org, 2013.

3. John Steadman, et al, "Effective and Efficient Use of the Fundamentals of Engineering Exam for Outcomes Assessment,” ASEE Annual Conference, Pittsburgh, PA, June, 2008

4. Drnevich, V., R. Tener, “Opposition to Mandatory Use of PE/FE Exams as Assessment Tools," ASEE Annual Conference, 1998

5. Criteria for Accrediting Engineering Programs, 2011 - 2012,

Engineering Accreditation Commission, ABET, October, 2010

6. Direct conversation between the author and Dr. Yonnie Chyung, August, 2009. 